\title{
A sensitive one-step TaqMan amplification approach for detection of rubella virus clade I and II genotypes in clinical samples
}

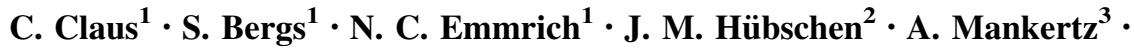 \\ U. G. Liebert ${ }^{1}$
}

Received: 11 July 2016/Accepted: 24 October 2016/Published online: 3 November 2016

(C) Springer-Verlag Wien 2016

\begin{abstract}
Although teratogenic rubella virus (RV) causes a vaccine-preventable disease, it is still endemic in several countries worldwide. Thus, there is a constant risk of RV importation into non-endemic areas. RV monitoring, especially during measles and Zika virus outbreaks, requires reliable diagnostic tools. For this study, a TaqMan-based one-step reverse transcription-quantitative PCR (RT-qPCR) assay, with the p90 gene as a novel and so far unexplored target for detection of clade I and II genotypes, was developed and evaluated. Automated nucleic acid extraction was carried out. Performance characteristics of the TaqMan RT-qPCR assay were determined for a RV plasmid standard and RNA extracted from virus-infected cell culture supernatants representing clade I and II genotypes. Diagnostic specificity and sensitivity were validated against other RNA and DNA viruses, relevant for RV diagnostic approaches and for RV-positive clinical samples, respectively. The assay is specific and highly sensitive with a limit of detection as low as five to one copies per reaction or 200 infectious virus particles per $\mathrm{ml}$. The coefficients of variation (CV) were specified as intra(within one run) and inter- (between different runs) assay
\end{abstract}

C. Claus and S. Bergs contributed equally.

C. Claus

claudia.claus@medizin.uni-leipzig.de

1 Institute of Virology, University of Leipzig, Leipzig, Germany

2 WHO European Regional Reference Laboratory for Measles and Rubella, Department of Infection and Immunity, Luxembourg Institute of Health, Esch-sur-Alzette, Luxembourg

3 WHO European Regional Reference Laboratory for Measles and Rubella, Robert Koch Institute, Berlin, Germany variation, and calculated based on the standard deviations for the obtained $\mathrm{Ct}$ values of the respective samples. Intraand inter-assay $\mathrm{CV}$ values were low, with a maximum of $3.4 \%$ and $2.4 \%$, respectively. The assay was shown to be suitable and specific for the analysis of clinical samples. With p90 as a novel target, the highly sensitive and specific TaqMan assay outlined in this study is suitable for RV diagnosis worldwide.

\section{Introduction}

Rubella virus (RV) causes the mild childhood disease rubella. However, after infection of susceptible women during the first trimester of pregnancy, embryonal and fetal death and teratogenic malformations, known as congenital rubella syndrome (CRS), occur with a very high frequency. The single plus-stranded RNA genome contains two open reading frames (ORF) located in the same translational frame (5'-p150-p90-3' for the non-structural ORF, and 5'C-E2-E1-3' for the structural ORF) [11, 20].

$\mathrm{RV}$ comprises only one serotype and two phylogenetic clades, which differ by 8 to $10 \%$ at the nucleotide (nt) level [28]. A $739 \mathrm{nt}$ fragment within the E1 region (nts 8,731 to $9,469)$ is recommended and sufficient for epidemiological analysis of RV [28]. Clade 1 is composed of nine recognized genotypes $(1 \mathrm{~B}, 1 \mathrm{C}, 1 \mathrm{D}, 1 \mathrm{E}, 1 \mathrm{~F}, 1 \mathrm{G}, 1 \mathrm{H}, 1 \mathrm{I}$, and $1 \mathrm{~J})$ and one provisional genotype 1a for strains circulating before 1984, such as the early vaccine strains, the RA $27 / 3$ vaccine strain, and the laboratory-adapted strain F-Therien [28]. Clade 2 comprises three recognized genotypes (2A, $2 \mathrm{~B}$, and $2 \mathrm{C}$ ). While most RV genotypes have a more restricted geographic distribution, genotypes $1 \mathrm{E}$ and $1 \mathrm{G}$, as well as $2 \mathrm{~B}$, are found worldwide [1, 28]. Despite the 
existence of an effective vaccine and a high overall $\mathrm{RV}$ immunization coverage in many European countries, susceptible cohorts with low vaccine-acquired immunity might represent a continuous risk for importation of RV from its endemic areas [18, 24]. Additionally, RV needs to be discriminated from other skin rash-associated diseases such as allergies and infections caused by viral pathogens, including parvovirus B19, measles virus and Zika virus $[8,26,28-30]$. In this regard, it needs to be considered that both RV and Zika virus cause a notable rate of asymptomatic infections. A clear verification of clinical cases is also the basis for assessment of the goals set by the WHO to control $\mathrm{RV}$, as rash/fever outbreaks continue to occur $[4,15,30]$.

\section{Objectives}

Due to the ongoing relevance of RV surveillance, including reliable laboratory confirmation of RV cases, this study was initiated to develop a sensitive TaqMan-based RTqPCR assay using p90 as a novel and so far unexplored target region. This assay was validated for different RV genotypes, including the currently circulating genotypes $1 \mathrm{E}, 1 \mathrm{G}$, and $2 \mathrm{~B}$, with regard to sensitivity (limit of detection and quantification) and specificity.

\section{Material and methods}

\section{Virus strains, virus infection and titration}

In addition to unnamed field isolates, three RV strains with a WHO identification, namely RVi/Gdansk.POL/14.07_0700426 (07-00426, genotype 1E), RVi/Prahova region.ROU/25.03_03-03703 (03-03703, genotype 1G), and RVi/ Wuerzburg.DEU/47.11_12-00009 (Wb-12, genotype 2B), were employed. RV cultivation and plaque assay were performed on Vero cells as described [5]. For the focus forming assay, the agarose overlay was removed and cells were fixed with $2 \%(\mathrm{w} / \mathrm{v})$ paraformaldehyde and permeabilized with ice-cold methanol (100\%). Thereafter, RVpositive serum was used as primary antibody and HRPconjugated goat-anti human IgG polyclonal as secondary antibody. The DAB SK-4100 Peroxide Substrate Kit (Vector Laboratories) was used according to the manufacturer's instructions. As a control for assay specificity, we used supernatants of: BHK21 cells, containing $5 \times 10^{9}$ genome copies/ml of tick-borne encephalitis virus, Vero cells, with either $5 \times 10^{7}$ genome copies/ml of Jeryl Lynn vaccine strain of mumps virus or $2 \times 10^{6}$ genome copies/ $\mathrm{ml}$ of Edmonston vaccine strain of measles virus, and Hep2 cells, containing $1 \times 10^{8}$ genome copies $/ \mathrm{ml}$ of
Coxsackievirus B1 strain. All cell culture supernatants were clarified by centrifugation.

\section{Samples and RNA extraction}

Cell culture supernatants and clinical samples were subjected to automated nucleic acid extraction with the MagNA Pure 96 system (Roche) at a volume of $200 \mu \mathrm{l}$, with an extraction control. An elution volume of $100 \mu \mathrm{l}$ was used, of which $5 \mu \mathrm{l}$ were used for TaqMan RT-qPCR.

\section{Primers and probe design and RV standard DNA and RNA}

Sequences for RV genotypes representing clade I and II were obtained from GenBank database and aligned using Geneious 5.4.3 software. Sequences and positions for the TaqMan probe and the corresponding oligonucleotides are given in Fig. 1. The TaqMan probe (TibMolBiol) was labelled at the 5', end with the reporter molecule 6-carboxyfluorescein (FAM) and with the BlackBerry Quencher (BBQ) at the 3' end. The plasmid Robo503 was used as RV standard DNA [27]. In vitro transcribed RNA was used as RNA standard and was obtained as follows: the oligonucleotide primers RV-235.s and RV_419.as (Fig. 1) were used to generate a PCR product with Robo503 as template, which was subsequently subcloned using the TOPO-TA cloning kit (Thermo Fisher Scientific), according to manufacturer's instructions. An in vitro transcription reaction was performed with $500 \mathrm{ng}$ of the XhoI-linearized plasmid template and SP6 polymerase using the Riboprobe in vitro transcription system (Promega) according to the manufacturer's instructions. Thereafter, DNase treatment and cleanup with QIAamp Viral RNA columns (Qiagen) were performed. RNA concentration was determined using the NanoDrop 1000 spectrophotometer.

\section{One-step singleplex quantitative real-time PCR set- up}

Each reaction contained: $5 \mu \mathrm{l}$ of the extracted RNA, water (no template control) or plasmid DNA, at the respective copy number, $10 \mu \mathrm{l}$ of the RT-qPCR master mix from the QuantiFast ${ }^{\circledR}$ Multiplex RT-PCR + R Kit (QIAGEN), $0.4 \mu \mathrm{M}$ of the sense and antisense primer, $0.2 \mu \mathrm{M}$ of TaqMan fluorogenic probe, and $20 \mathrm{U}$ of RNase Inhibitor (Fermentas), in a total volume of $20 \mu \mathrm{l}$. RT-qPCR was performed in a carousel-based LightCycler 2.0 (Roche) with the following cycling conditions: one cycle of reverse transcription at $50{ }^{\circ} \mathrm{C}$ for $20 \mathrm{~min}$, one cycle of activation at $95{ }^{\circ} \mathrm{C}$ for $5 \mathrm{~min}$, followed by 45 cycles of denaturation at $95{ }^{\circ} \mathrm{C}$ for $15 \mathrm{sec}$, of annealing/extension at $60{ }^{\circ} \mathrm{C}$ for $20 \mathrm{sec}$ combined with the detection step $(530 \mathrm{~nm})$. 

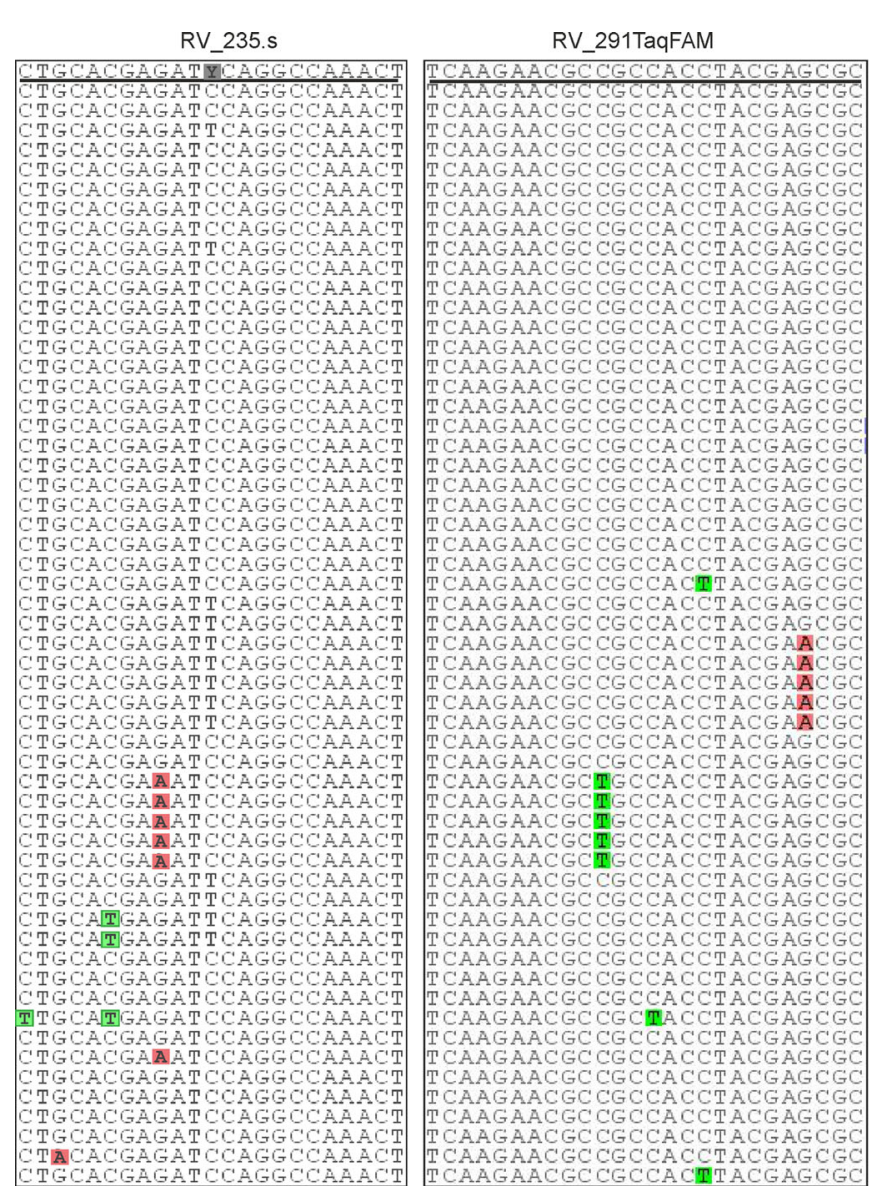

Fig. 1 Alignment of the conserved p90 target sequence selected for primer and TaqMan probe design. All sequences available in GenBank for this region were used for this alignment to achieve an in depth in silico analysis. Sequences of the deduced primers and the

\section{One-step singleplex quantitative real-time PCR performance characteristics}

Plasmid DNA copy numbers were calculated according to the following formula (http://cels.uri.edu/gsc/cndna. html) [14]:

$$
\text { Numberofcopies }=\frac{6.022 \times 10^{23}\left(\frac{\text { copies }}{\text { mol }}\right) \times \text { DNAamount }\left(\frac{n g}{\mu l}\right)}{\text { DNAlength }(b p) \times 10^{9}\left(\frac{n g}{g}\right) \times 660\left(\frac{g / m o l}{b p}\right)}
$$

The copy numbers of the RNA standard were quantified accordingly, but based on the average molecular mass of $340 \mathrm{Da}$ for 1 nucleotide of single-stranded RNA. After this initial calculation, the copy number of the serial dilutions of the RNA standard were adapted to the $\mathrm{Ct}$ values obtained for the dilutions of the DNA standard and the regression equations from the resulting standard curve.

Amplification efficiency (E) was determined through the equation $\mathrm{E}=10^{-1 / \text { slope }}$ and converted into percentage according to the formula $(\mathrm{E}-1) \times 100 \%$. The coefficient of

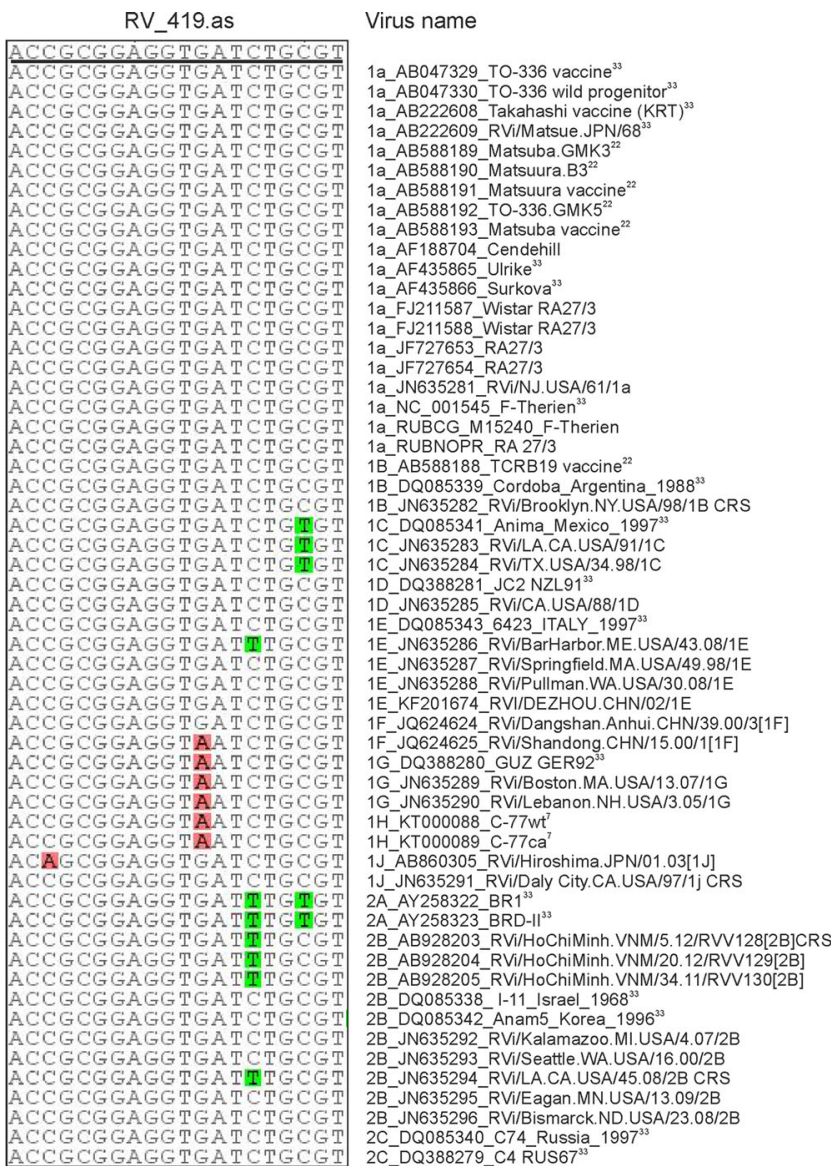

TaqMan probe are given and nt positions refer to $\mathrm{p} 90$ gene sequence. Genotypes were assigned according to GenBank accession numbers or to indicated publications $[7,22,33]$. s, sense primer; as, antisense primer

variation was calculated according to the following formula: $\mathrm{CV}=(\mathrm{SD}[\mathrm{Ct}$-value $] /$ overall mean $[\mathrm{Ct}$-value $]) \times$ 100 [9].

\section{Limit of detection and limit of quantification}

The analytical sensitivity or limit of detection (LOD) refers to the lowest possible concentration of the amplification target that is tested positive in $\geq 95 \%$ of the assay runs, while the limit of quantification (LOQ) relates to the lowest concentration of the target that is still within the linear range [16]. The LOD was calculated through Probit analysis, performed with JMP software, version 12. The Probit method was used to generate a graph, through which LOD can be deduced at the $95 \%$ probability for a positive response [21].

\section{Generation of figures}

The figures in this manuscript were edited with CorelDRAW X7 graphics software. 


\section{Results}

\section{Performance characteristics of TaqMan-based RT- qPCR targeting RV p90 gene}

The cycle threshold $(\mathrm{Ct})$ values obtained for the ten-fold serial dilutions of the RV plasmid DNA standard ranged from 11 to 37.5 cycles (Fig. 2). Linearity was present over eight $\log$ units with a mean correlation coefficient $\left(\mathrm{R}^{2}\right)$ of 0.9988 (slope $=-3.573$ ) and a mean amplification efficiency of $91 \%$ (Fig. 2 and Table 1).

\section{Precision of the TaqMan-based approach: intra- assay repeatability and inter-assay reproducibility}

The intra-assay repeatability and the inter-assay reproducibility were assessed through triplicate samples in five different experiments with ten-fold serial dilutions of the RV DNA standard ranging from $1 \times 10^{8}$ to $1 \times 10^{1}$ copies (Tables 1 and 2). The coefficients of variation (CVs) of the TaqMan-based RT-qPCR are defined as the standard deviation $(\mathrm{SD})$ of the obtained $\mathrm{Ct}$ values and ranged from 0.08 to $3.39 \%$ and from 0.67 to $2.42 \%$ for the intra- and inter-assay CVs, respectively.

\section{Limit of detection and quantification}

For determination of the analytical LOD and LOQ, the regression curves obtained for ten-fold serial dilutions of RNA extracted from cell culture supernatants infected with RV strains Wb-12 and 03-03703 were plotted against the RNA standard and the mean $\mathrm{Ct}$ values gained for the five independent runs of the RV plasmid standard (Fig. 3).

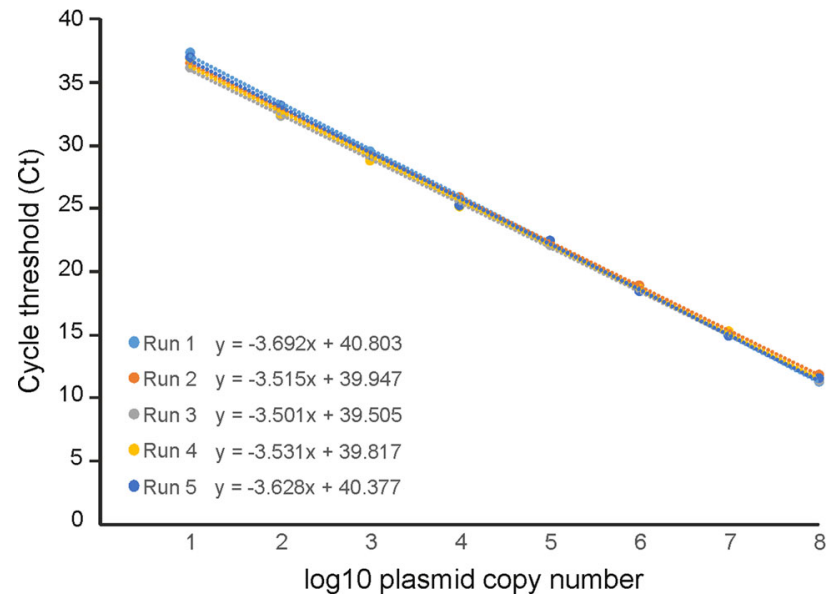

Fig. 2 Standard curve obtained through ten-fold serial dilutions of plasmid standard DNA. Five independent experiments, with triplicates of each sample, are shown
Although LOD and LOQ are internal characteristics for the TaqMan assay, different template materials were used as only extracted viral RNA, besides the RNA standard, takes the RT step of the assay into account. The resulting regression curves showed comparable performance characteristics (slope and $\mathrm{R}^{2}$ values) and linearity was present until one $\log 10$ copies (Fig. 3), revealing an LOQ of 10 copies per reaction for the RV strains and a mean of 64 copies for the plasmid DNA standard.

For a more accurate estimation of the LOD, two-fold dilutions of the DNA and RNA standards ( 25 to 0.39 copies per reaction) and of RNA extracted from the supernatants of Vero cells infected with the Wb-12 strain were used (Table 3). In this case, the analytical LOD was between 1 and 3 copies per reaction. Based on Probit analysis (Fig. 4), the LOD at the 0.95 probability for a positive reponse was determined as 1 (for extracted Wb-12 viral RNA and DNA standard) and 5 (for the RNA standard) copies per reaction.

\section{Analytical and diagnostic sensitivity}

To evaluate if the characteristic parameters seen so far with the RV DNA and RNA standard can be obtained also with RV clade I and II strains, ten-fold serial dilutions of RNA extracted from cell culture supernatants infected with different RV strains were used. As a control, the Therien strain, from which the cDNA plasmid Robo503 was originally derived, was used. Performance parameters of the obtained standard curves are summarized in Table 4. The amplification efficiency was in the range of $92 \%$ and $101 \%$. The slope and $\mathrm{R}^{2}$ values were also comparable between the examined RV strains and within the range of the RV DNA standard. Thereafter spike experiments were executed through addition of 10 -fold serial dilutions of a supernatant of the 03-03-703 strain $\left(10^{6}\right.$ infectious virus particles per $\mathrm{ml}$ ) either to oral fluid from a healthy donor or PBS. Each of these dilutions was subjected separately to nucleic acid extraction by MagnaPure technology. A minimum of approximately 200 viral particles per $\mathrm{ml}$ were detectable for each type of fluid, thus excluding interference of the oral microenvironment with the TaqMan assay. For diagnostic sensitivity RV-positive clinical samples were analyzed by the p90-based TaqMan assay. Genotypes $1 \mathrm{H}, 1 \mathrm{E}$ and $2 \mathrm{~B}$ were readily detectable (Table 5).

\section{Analytical and diagnostic specificity}

To verify analytical specificity of the RV TaqMan qPCR approach, cell culture supernatants containing between $10^{9}$ and $10^{6}$ genome copies/ml of measles virus, Coxsackievirus B1, FSME, or mumps virus, were subjected to RNA 
Table 1 Intra-assay reproducibility of the TaqMan-based RT-qPCR assay (for each run: $\mathrm{n}=3$ )

\begin{tabular}{|c|c|c|c|c|c|c|c|c|c|c|c|c|}
\hline & \multicolumn{4}{|c|}{$\begin{array}{l}\text { Run } 1 \text { (efficiency: } 87 \% \text {; slope: }-3.692 ; \\
\mathrm{R}^{2}=0.999 \text { ) }\end{array}$} & \multicolumn{4}{|c|}{$\begin{array}{l}\text { Run } 2 \text { (efficiency: } 93 \% \text {; slope: }-3.515 \\
\mathrm{R}^{2}=0.999 \text { ) }\end{array}$} & \multicolumn{4}{|c|}{$\begin{array}{l}\text { Run } 3 \text { (efficiency: } 93 \% \text {; slope: }-3.501 ; \\
\mathrm{R}^{2}=0.999 \text { ) }\end{array}$} \\
\hline & Mean copy no. & $\mathrm{Ct}$ mean & SD & $\mathrm{CV}$ & Mean copy no. & $\mathrm{Ct}$ mean & SD & $\mathrm{CV}$ & Mean copy no. & $\mathrm{Ct}$ mean & SD & $\mathrm{CV}$ \\
\hline $10^{8}$ & $125,000,000$ & 11.33 & 0.26 & 2.27 & $106,000,000$ & 11.88 & 0.01 & 0.08 & $107,266,667$ & 11.39 & 0.28 & 2.44 \\
\hline $10^{7}$ & $11,166,667$ & 15.01 & 0.09 & 0.60 & $11,166,667$ & 15.25 & 0.11 & 0.74 & $9,923,333$ & 15.01 & 0.08 & 0.54 \\
\hline $10^{6}$ & 962,000 & 18.77 & 0.10 & 0.54 & 959,333 & 18.93 & 0.28 & 1.49 & 907,000 & 18.69 & 0.31 & 1.67 \\
\hline $10^{5}$ & 105,667 & 22.15 & 0.05 & 0.23 & 89,933 & 22.47 & 0.18 & 0.80 & 92,833 & 22.16 & 0.16 & 0.70 \\
\hline $10^{4}$ & 85,63 & 26.00 & 0.10 & 0.37 & 8,757 & 25.95 & 0.08 & 0.32 & 11,583 & 25.37 & 0.39 & 1.55 \\
\hline $10^{3}$ & 812 & 29.62 & 0.27 & 0.92 & 1,199 & 28.97 & 0.48 & 1.65 & 1,210 & 28.81 & 0.31 & 1.08 \\
\hline $10^{2}$ & 78 & 33.19 & 0.07 & 0.21 & 80 & 32.98 & 0.27 & 0.81 & 65 & 32.36 & 0.83 & 2.56 \\
\hline \multirow[t]{3}{*}{$10^{1}$} & 5 & 37.45 & 0.90 & 2.41 & 7 & 36.60 & 0.18 & 0.50 & 9 & 36.21 & 0.10 & 0.29 \\
\hline & \multicolumn{5}{|c|}{ Run 4 (efficiency: $92 \%$; slope: $-3.531 ; \mathrm{R}^{2}=0.998$ ) } & \multicolumn{5}{|c|}{ Run 5 (efficiency: 89\%; slope: $-3.628 ; \mathrm{R}^{2}=0.999$ ) } & & \\
\hline & Mean copy no. & $\mathrm{Ct} \mathrm{m}$ & & SD & $\mathrm{CV}$ & Mean copy $n$ & & $\mathrm{Ct}$ mean & SD & $\mathrm{CV}$ & & \\
\hline $10^{8}$ & $110,666,667$ & 11.5 & & 0.11 & 0.93 & $124,000,000$ & & 11.58 & 0.31 & 2.68 & & \\
\hline $10^{7}$ & $9,063,333$ & 15.3 & & 0.46 & 2.99 & $12,033,333$ & & 14.97 & 0.22 & 1.44 & & \\
\hline $10^{6}$ & 984,000 & 18.6 & & 0.14 & 0.77 & $1,096,667$ & & 18.50 & 0.16 & 0.87 & & \\
\hline $10^{5}$ & 87,400 & 22.3 & & 0.20 & 0.92 & 78,167 & & 22.51 & 0.76 & 3.39 & & \\
\hline $10^{4}$ & 13,100 & 25.1 & & 0.28 & 1.13 & 11,530 & & 25.28 & 0.53 & 2.10 & & \\
\hline $10^{3}$ & 1,162 & 28.8 & & 0.36 & 1.26 & 733 & & 29.32 & 0.35 & 1.18 & & \\
\hline $10^{2}$ & 94 & 32.5 & & 0.36 & 1.12 & 65 & & 33.17 & 1.10 & 3.32 & & \\
\hline $10^{1}$ & 6 & 36.9 & & 1.25 & 3.38 & 4 & & 37.08 & 0.49 & 1.33 & & \\
\hline
\end{tabular}

no., number

Table 2 Inter-assay reproducibility of the TaqMan-based RT-qPCR $(n=5)$ was determined through analysis of ten-fold serial dilutions of the RV plasmid DNA standard

\begin{tabular}{lrlll}
\hline Copy number & Mean copy number & Mean $C_{t}$ & Mean SD & CV \\
\hline $100,000,000$ & $114,586,667$ & 11.55 & 0.19 & 1.67 \\
$10,000,000$ & $10,670,667$ & 15.12 & 0.16 & 1.07 \\
$1,000,000$ & 981,800 & 18.71 & 0.14 & 0.76 \\
100,000 & 90,800 & 22.32 & 0.14 & 0.67 \\
10,000 & 10,707 & 25.55 & 0.35 & 1.37 \\
1,000 & 1,023 & 29.11 & 0.31 & 1.09 \\
100 & 76 & 32.86 & 0.33 & 1.01 \\
10 & 6 & 36.85 & 0.42 & 1.15 \\
1 & 4 & 37.97 & 0.91 & 2.42 \\
\hline
\end{tabular}

extraction. Additionally, human samples obtained from healthy individuals and clinical samples tested positive for measles and parvovirus B19 were analyzed (Table 5). Especially measles and parvovirus B19 are relevant as they have clinical symptoms similar to RV. No amplification signal, and thus no cross-reactivity, was obtained in any of the samples tested.

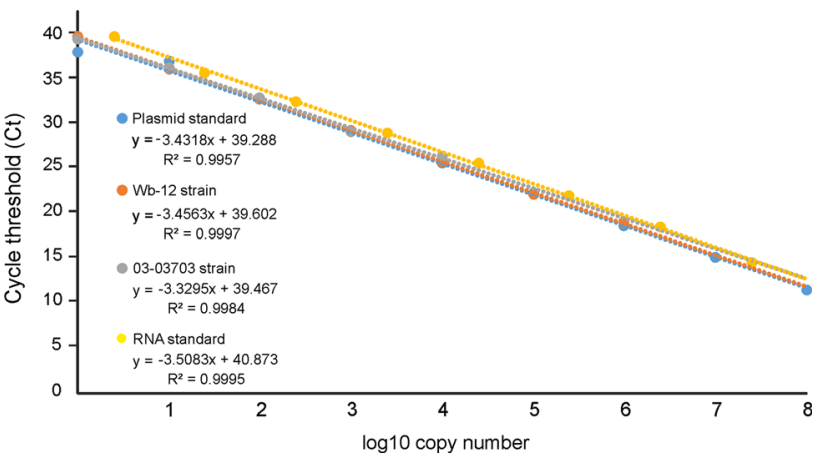

Fig. 3 Standard curve obtained through ten-fold serial dilutions of viral RNA for Wb-12 and 03-03703 strains and the RNA standard. The regression curve for plasmid standard DNA was based on the mean $\mathrm{Ct}$ values from five independent runs with triplicates of each sample shown in Fig. 2

\section{Relationship between infectious titer and genome copies}

To analyze whether the amount of genome copies in clinical samples can be used as an indication for infectious virus particles, supernatants of RV-infected Vero cells were processed to determine this ratio (Fig. 5). Therien and Wb-12 strains show cytopathogenicity on Vero cells and were 
Table 3 Determination of the limit of detection (LOD) through analysis of two-fold dilutions of RV plasmid DNA (DNA standard), in vitro transcribed RNA (RNA standard) and extracted viral RNA for the indicated RV strain

\begin{tabular}{|c|c|c|c|c|c|}
\hline & Copy number & Mean copy number ${ }^{\mathrm{a}}$ & Mean $\mathrm{Ct}$ & SD & Positives/run \\
\hline \multirow[t]{6}{*}{ DNA standard } & 25 & 22.67 & 34.93 & 0.83 & $10 / 10$ \\
\hline & 12.5 & 15.26 & 35.85 & 0.58 & $10 / 10$ \\
\hline & 6.25 & 4.43 & 37.29 & 0.57 & $10 / 10$ \\
\hline & 3.125 & 1.54 & 39.86 & 1.64 & $10 / 10^{\mathrm{b}}$ \\
\hline & 1.563 & 1.37 & 39.87 & 1.32 & $9 / 10$ \\
\hline & 0.781 & 0.79 & 41.18 & 1.70 & $6 / 10$ \\
\hline \multirow[t]{6}{*}{ RNA standard } & & 24.29 & 36.66 & 0.51 & $10 / 10$ \\
\hline & & 9.31 & 38.40 & 1.18 & $10 / 10$ \\
\hline & & 4.63 & 39.30 & 0.96 & $10 / 10$ \\
\hline & & 3.43 & 40.03 & 1.98 & $10 / 10^{\mathrm{b}}$ \\
\hline & & 4.22 & 40.40 & 3.16 & $5 / 10$ \\
\hline & & n. d. & n. d. & n. a. & $0 / 10$ \\
\hline \multirow[t]{6}{*}{ Wb-12 } & & 20.41 & 35.84 & 0.62 & $10 / 10$ \\
\hline & & 12.07 & 36.58 & 0.49 & $10 / 10$ \\
\hline & & 7.50 & 37.29 & 0.50 & $10 / 10$ \\
\hline & & 2.04 & 39.90 & 1.92 & $10 / 10^{\mathrm{b}}$ \\
\hline & & 1.20 & 40.06 & 0.86 & $9 / 10$ \\
\hline & & 0.66 & 41.04 & 0.96 & $4 / 10$ \\
\hline
\end{tabular}

n. d., not detected; n. a., not applicable

${ }^{a}$ Calculation of the copy number was based on the $\mathrm{Ct}$ values obtained for the plasmid DNA dilutions and the regression equations from the resulting standard curve

${ }^{b}$ LOD
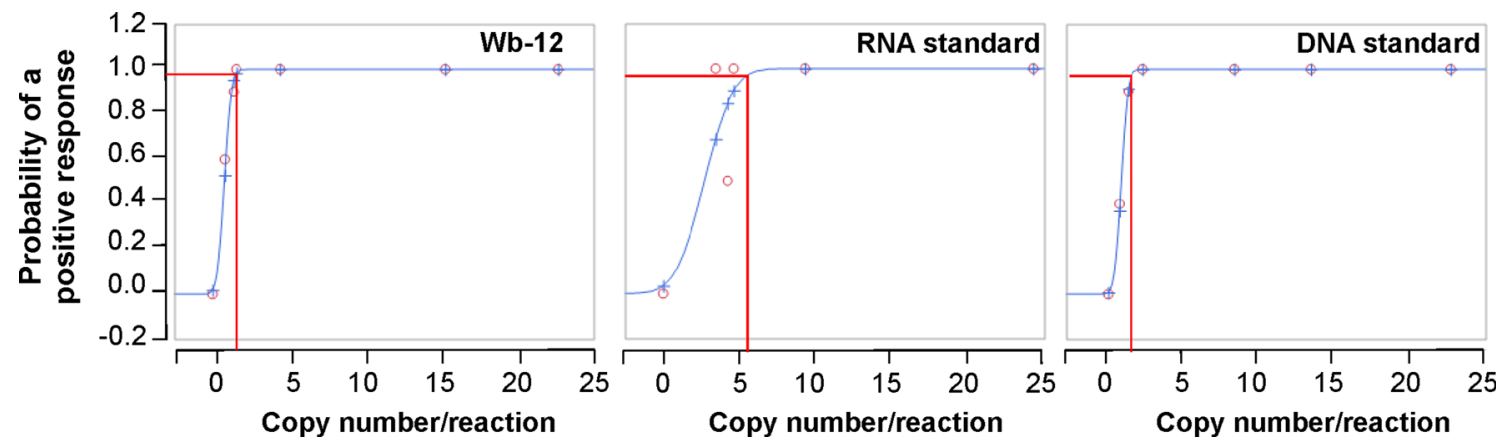

Fig. 4 Probit analysis for the indicated samples was used to verify the limit of detection at the 95\% probability of a positive response. Ten replicates were used per copy number

compared to 03-03703 strain, which lacks signs of cytopathogenicity. After initial infection, extensive washing was performed to remove unattached virus. Figure 5 highlights that the number of genome copies is almost two log 10 units higher than the amount of infectious virus particles, but only for the strains associated with cytopathogenicity.

\section{Discussion}

$\mathrm{RV}$ diagnostics is based on serological tests for rubella $\operatorname{IgM}$ and $\mathrm{IgG}$, detection and quantification of $\mathrm{RV}$ genomic RNAs, and, ideally, virus isolation from clinical specimens, such as urine or nasopharyngeal swabs [15]. This study presents the first TaqMan-based RT-qPCR using p90 as a template region and extends established protocols based on E1 [31, 32], the capsid protein region [3] or p150 $[2,12,19]$. This highly conserved region within $\mathrm{p} 90$ has a GC content of 54 to $65 \%$, which, in contrast to the average value of $70 \%$, is more suitable for a TaqMan probe design. Validated RT-qPCRs with different target regions are suitable to cover possible sequence variations among circulating RV strains, which were already reported to occur [2]. Despite a suitable GC content for primer design, E1 is one of the less well conserved regions within the RV genome [6]. This study confirmed p90 as a target for a one- 
Table 4 Comparison of correlation between infectious titer of RV strains and genome copies

Table 5 Detection of RV in clinical samples by the TaqMan approach targeting p90 gene sequence

\begin{tabular}{|c|c|c|c|c|c|}
\hline \multirow[t]{2}{*}{ Strain } & \multicolumn{2}{|l|}{ Starting dilution $10^{\circ}$} & \multicolumn{3}{|c|}{ Performance characteristics } \\
\hline & RT-qPCR (copies/ml) & Titer & Efficiency $(\%)$ & Slope & $\mathrm{R}^{2}$ value \\
\hline Therien & $1.6 \times 10^{8}$ & $3.0 \times 10^{6} \mathrm{PFU} / \mathrm{ml}$ & 92 & -3.519 & 0.998 \\
\hline $1 \mathrm{C}$ & $1.3 \times 10^{8}$ & $2.5 \times 10^{6} \mathrm{FFU} / \mathrm{ml}$ & 94 & -3.464 & 0.994 \\
\hline $1 \mathrm{D}$ & $4.7 \times 10^{8}$ & $\begin{array}{l}4.0 \times 10^{6} \\
\mathrm{FFU} / \mathrm{ml}\end{array}$ & 100 & -3.315 & 0.997 \\
\hline $1 \mathrm{E}(07-00426)$ & $4.7 \times 10^{7}$ & $\begin{array}{l}2.7 \times 10^{6} \\
\mathrm{FFU} / \mathrm{ml}\end{array}$ & 96 & -3.409 & 0.997 \\
\hline $1 \mathrm{G}(03-03703)$ & $2.8 \times 10^{6}$ & $\begin{array}{l}4.5 \times 10^{6} \\
\mathrm{FFU} / \mathrm{ml}\end{array}$ & 101 & -3.298 & 0.997 \\
\hline $1 \mathrm{H}$ & $5.9 \times 10^{7}$ & $\begin{array}{l}5.0 \times 10^{6} \\
\mathrm{FFU} / \mathrm{ml}\end{array}$ & 93 & -3.494 & 0.996 \\
\hline 2B (Wb-12) & $8.9 \times 10^{6}$ & $\begin{array}{l}7.0 \times 10^{6} \\
\mathrm{PFU} / \mathrm{ml}\end{array}$ & 93 & -3.502 & 0.999 \\
\hline
\end{tabular}

The assay involved ten-fold serial dilutions of the RNA extracted from cell culture supernatants infected with the indicated RV genotypes. Plaque- (PFU) or focus-forming units (FFU) per $\mathrm{ml}$ correspond to the infectious titer obtained for the cell culture supernatant prior to RNA extraction. Based on Figure 3, the efficiencies for the DNA and RNA standard were $91 \%$ and $93 \%$, respectively. A slope of -3.4318 and 3.5083 and a value of 0.9957 and 0.9995 for $\mathrm{R}^{2}$ were obtained for the DNA and RNA standard, respectively

\begin{tabular}{lllll}
\hline Sample no. & Type of specimen & Virus (genotype) & Ct & Copies/ml \\
\hline 1 & Urine & RV (2B) & 37.55 & 187 \\
2 & Respiratory swab & RV (2B) & 31.02 & $1.5 \times 10^{4}$ \\
3 & Oral fluid & RV (2B) & 35.94 & 560 \\
4 & Swab & RV (2B) & 33.66 & $2.6 \times 10^{3}$ \\
5 & Nasopharyngeal swab & RV (1H) & 36.42 & 400 \\
6 & Nasopharyngeal swab & RV (1E) & 38.38 & 110 \\
7 & Nasopharyngeal swab & RV (1E) & 37.10 & 250 \\
8 & Urine & MV (B3) & & Neg. \\
9 & Throat swab & MV (D4) & & Neg. \\
10 & Swab & MV (D8) & & Neg. \\
11 & Urine & MV (B3) & Neg. \\
12 & Oral fluid & MV (B3) & & Neg. \\
13 & Serum & B19 (3a) & & Neg. \\
14 & Serum & B19 (1a) & & Neg. \\
15 & Urine & Neg. & & Neg. \\
16 & Oral fluid & Neg. & & \\
\hline
\end{tabular}

Samples were classified as MV- and Parvovirus B19-positive by PCR. Corresponding samples from healthy individuals were employed as controls

no., number; neg., negative step TaqMan-based RT-PCR assay for quantification of $\mathrm{RV}$, which was not only validated through a DNA standard, but also by using RV-positive patient samples, as well as RNA extracted from cell culture supernatants, which is an accepted substitute for in vitro transcribed RNA. Both types of RNA produce similar results regarding sensitivity of real-time PCRs using TaqMan chemistry [17]. The results outlined in this study are consistent with this notion, as extracted Therien RNA had performance characteristics similar to the one observed for the RNA standard. There are only a few studies which used extracted RNAs for some [19] or even all RV genotypes [2] to validate RT-qPCR assays. Although our study lacks some of the RV genotypes, the three currently circulating genotypes $(1 \mathrm{E}, 1 \mathrm{G}$, and $2 \mathrm{~B}$ ) with a global distribution are included [1, 23]. Furthermore, an in-depth and comprehensive in silico 
Fig. 5 Analysis of the ratio (depicted as diamonds) between viral genome copies, determined by TaqMan assay, and infectious virus particles, quantified by plaque assay (PFU or $\mathrm{FFU} / \mathrm{ml}$ ), for the indicated virus strains over the indicated time of culture $(n=2)$. dpi, days post-infection; MOI, multiplicity of infection

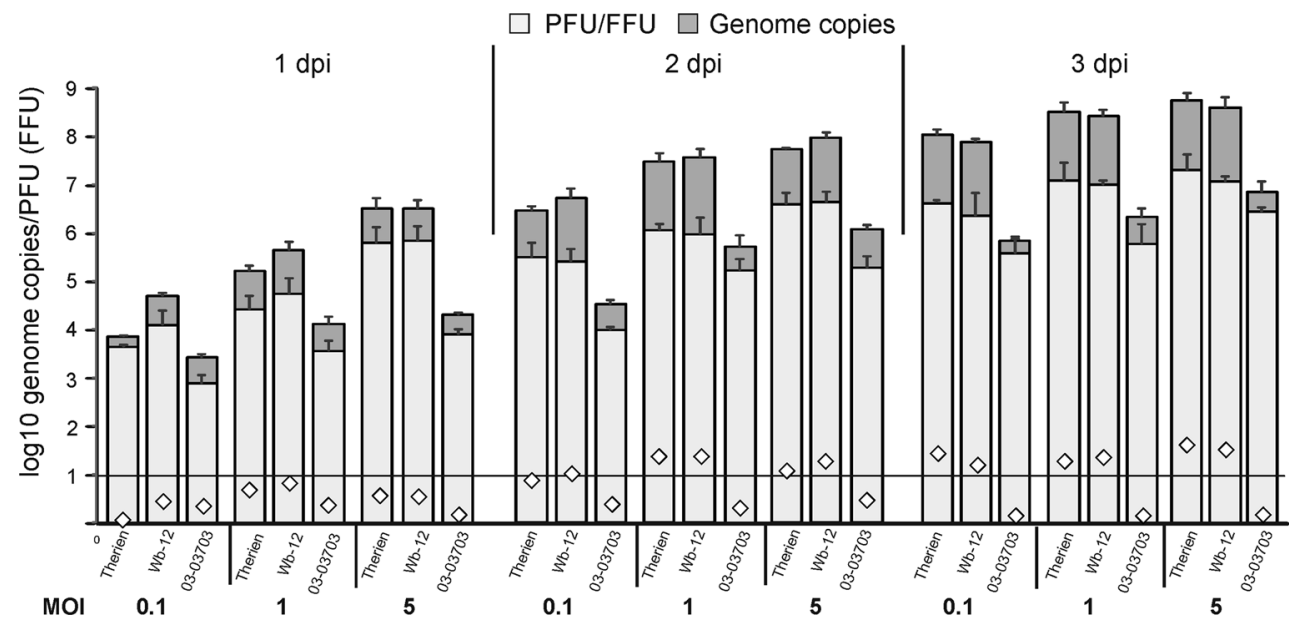

analysis was performed for additional RV genotypes and viruses relevant for RV differential diagnostics, such as alphaviruses and Zika virus. Moreover, a study on a p150based RT-LAMP assay applied to different RV genotypes generally showed a slightly lower sensitivity than TaqMan based RT-qPCRs, including the one outlined in this study [2]. With one to five copies per reaction the RT-qPCR assay illustrated in this publication has a comparable or slightly higher sensitivity than previous studies. The multiplex TaqMan PCR described for simultaneous detection of RV and measles virus quantified as low as 10 copies of plasmid DNA per run [12]. Another study targeting p150 had a limit of detection of 10 copies of in vitro synthesized control RNA [19]. However, these assays are hard to compare as they have been optimized on various platforms. In comparison to previous studies, the primer and probe design outlined here was based on a large number of RV sequences and validated for a considerable number of RV cell culture isolates, in addition to clinical samples representing various RV genotypes. Although some RV strainspecific mismatches between oligonucleotide primer/TaqMan probe and the template are apparent, they are not within the 3 '-end region. Thus, they are not expected to affect performance characteristics of the outlined TaqMan assay.

The slopes for the one-step singleplex RT-qPCR assays obtained for the RV plasmid DNA and RNA standard and the RNA extracted from supernatants of RV-infected Vero cells were within the acceptable range $(-3.6 \leq \mathrm{m} \leq-3.1)$, which is also reflected in the obtained efficiency $(90 \%<\mathrm{E}<110 \%)$ and the coefficient of correlation $\left(0.99 \leq \mathrm{R}^{2} \leq 0.999\right)$ [25]. Assay specificity was experimentally assessed for measles virus and parvovirus B19, which are relevant viruses as they can cause a skin rash similar to RV.

The spiking experiment extends the suitability of the MagNAPure technology as a validated automatic nucleic acid extraction method for viral RNA [13] to RV diagnostics, which was so far mainly based on reports employing sample processing by QIAamp Viral RNA Mini kit $[3,12]$. The detection limit of 200 virus particles per $\mathrm{ml}$ is in agreement with the detection limit of our TaqMan PCR of one to five copies per reaction, which equals to 100 to 400 copies per milliliter of original sample. This detection limit for RV RNA extraction by MagNAPure was comparable to the QIAamp Viral RNA Mini kit (data not shown).

Virus diagnostics also involves the question whether RT-qPCR data could be used as an indication for virus infectious units. While the ratio of infectious virions to genome copies is hardly one to one, due to the generation of defective interfering viral particles, a correlation between these two parameters was reported for yellow fever virus [10]. In this study, the number of PFU or FFU per $\mathrm{ml}$, as a calculation of infectious virus particles, was contrasted over time of culture to genome copies per $\mathrm{ml}$ for different RV strains with or without cytopathogenicity on Vero cells. We could extend the initial report on viral genome to CCID50 ratio [3] through the observation that genome to PFU/FFU ratio is considerably low, but only for a non-cytopathogenic RV strain. This is also the case during the exponential phase of $\mathrm{RV}$ replication. Therefore the already discussed cell destruction [3] appears to be a likely contributor for the discrepancy between these two parameters, but through this study such an association can be assigned as rather strain-specific. However, most of the clinical RV strains lack signs of cytopathogenicity on susceptible cell lines, thus genome copy number in clinical samples likely correlates with the amount of infectious virus particles.

In conclusion, we have presented a TaqMan-based RTqPCR assay with high sensitivity ( 1 to 5 copies per reaction), specificity (100\%) and inter-assay reproducibility (inter-assay $\mathrm{CV}$ is between 0.7 and $2.4 \%$ ). These characteristics make this new TaqMan approach particularly 
useful. Rapid and reliable diagnosis of RV with a high sensitivity is the basis for successful diagnostics and epidemiological surveillance.

Acknowledgements The authors wish to thank Dr. Corinna Pietsch for careful reading of the manuscript and Dr. B. Weißbrich, University of Wuerzburg, Germany for providing the Wb-12 strain.

\section{Compliance with ethical standards}

Funding No funding was received for this study.

Conflict of interest The authors declare that they have no conflict of interest.

Informed consent For this type of study formal consent is not required, as it did not involve individual participants.

Research involving human participants and/or animals This manuscript does not contain any studies with human participants or with animals performed by any of the authors.

\section{References}

1. Abernathy ES, Hubschen JM, Muller CP, Jin L, Brown D, Komase K, Mori Y, Xu W, Zhu Z, Siqueira MM, Shulga S, Tikhonova N, Pattamadilok S, Incomserb P, Smit SB, AkouaKoffi C, Bwogi J, Lim WW, Woo GK, Triki H, Jee Y, Mulders MN, de Filippis AM, Ahmed H, Ramamurty N, Featherstone D, Icenogle JP (2011) Status of global virologic surveillance for rubella viruses. J Infect Dis 204(Suppl 1):S524-S532

2. Abo H, Okamoto K, Anraku M, Otsuki N, Sakata M, Icenogle J, Zheng Q, Kurata T, Kase T, Komase K, Takeda M, Mori Y (2014) Development of an improved RT-LAMP assay for detection of currently circulating rubella viruses. J Virol Methods 207:73-77

3. Ammour Y, Faizuloev E, Borisova T, Nikonova A, Dmitriev G, Lobodanov S, Zverev V (2013) Quantification of measles, mumps and rubella viruses using real-time quantitative TaqManbased RT-PCR assay. J Virol Methods 187:57-64

4. Centers for Disease C, Prevention (2013) Rubella and congenital rubella syndrome control and elimination-global progress, 2000-2012. MMWR Morb Mortal Wkly Rep 62:983-986

5. Claus C, Hofmann J, Uberla K, Liebert UG (2006) Rubella virus pseudotypes and a cell-cell fusion assay as tools for functional analysis of the rubella virus E2 and E1 envelope glycoproteins. J Gen Virol 87:3029-3037

6. Cloete LJ, Tanov EP, Muhire BM, Martin DP, Harkins GW (2014) The influence of secondary structure, selection and recombination on rubella virus nucleotide substitution rate estimates. Virol J 11:166

7. Dmitriev GV, Borisova TK, Faizuloev EB, Zabiyaka YI, Desyatskova RG, Zverev VV (2012) A study of molecular mechanisms of rubella virus attenuation evidenced from the Russian C-77 strain. Mol Genet Microbiol 27:120-126

8. Duffy, Chen TH, Hancock WT, Powers AM, Kool JL, Lanciotti RS, Pretrick M, Marfel M, Holzbauer S, Dubray C, Guillaumot L, Griggs A, Bel M, Lambert AJ, Laven J, Kosoy O, Panella A, Biggerstaff BJ, Fischer M, Hayes EB (2009) Zika virus outbreak on Yap Island, Federated States of Micronesia. N Engl J Med 360:2536-2543

9. Fellahi S, El Harrak M, Kuhn JH, Sebbar G, el Bouaiti A, Khataby K, Fihri OF, El Houadfi M, Ennaji MM (2016) Comparison of SYBR green I real-time RT-PCR with conventional agarose gel-based RT-PCR for the diagnosis of infectious bronchitis virus infection in chickens in Morocco. BMC Res Notes 9:231

10. Fernandes-Monteiro AG, Trindade GF, Yamamura AM, Moreira OC, de Paula VS, Duarte AC, Britto C, Lima SM (2015) New approaches for the standardization and validation of a real-time qPCR assay using TaqMan probes for quantification of yellow fever virus on clinical samples with high quality parameters. Hum Vaccin Immunother 11(7):1865-1871. doi:10.4161/21645515. 2014.990854

11. Frey TK (1994) Molecular biology of rubella virus. Adv Virus Res 44:69-160

12. Hubschen JM, Kremer JR, De Landtsheer S, Muller CP (2008) A multiplex TaqMan PCR assay for the detection of measles and rubella virus. J Virol Methods 149:246-250

13. Knepp JH, Geahr MA, Forman MS, Valsamakis A (2003) Comparison of automated and manual nucleic acid extraction methods for detection of enterovirus RNA. J Clin Microbiol 41:3532-3536

14. Kuhar U, Barlic-Maganja D, Grom J (2013) Development and validation of TaqMan probe based real time PCR assays for the specific detection of genotype A and B small ruminant lentivirus strains. BMC Vet Res 9:172

15. Lambert N, Strebel P, Orenstein W, Icenogle J, Poland GA (2015) Rubella. Lancet 385:2297-2307

16. Linnet K, Kondratovich M (2004) Partly nonparametric approach for determining the limit of detection. Clin Chem 50:732-740

17. Lopez-Vazquez C, Bandin I, Dopazo CP (2015) Real-time RTPCR for detection, identification and absolute quantification of viral haemorrhagic septicaemia virus using different types of standards. Dis Aquat Org 114:99-116

18. Macey JF, Tam T, Lipskie T, Tipples G, Eisbrenner T (2011) Rubella elimination, the Canadian experience. J Infect Dis 204(Suppl 2):S585-S592

19. Okamoto K, Fujii K, Komase K (2010) Development of a novel TaqMan real-time PCR assay for detecting rubella virus RNA. J Virol Methods 168:267-271

20. Oker-Blom C (1984) The gene order for rubella virus structural proteins is NH2-C-E2-E1-COOH. J Virol 51:354-358

21. Omar SV, Roth A, Ismail NA, Erasmus L, Ehlers M, Kock M, Paulse N, Said HM, Hoosen AA, Reischl U (2011) Analytical performance of the Roche LightCycler ${ }^{\circledR}$ mycobacterium detection kit for the diagnosis of clinically important mycobacterial species. PLoS One 6(9):e24789. doi:10.1371/journal.pone.0024789

22. Otsuki N, Abo H, Kubota T, Mori Y, Umino Y, Okamoto K, Takeda M, Komase K (2011) Elucidation of the full genetic information of Japanese rubella vaccines and the genetic changes associated with in vitro and in vivo vaccine virus phenotypes. Vaccine 29:1863-1873

23. Padhi A, Ma L (2014) Molecular evolutionary and epidemiological dynamics of genotypes $1 \mathrm{G}$ and $2 \mathrm{~B}$ of rubella virus. PloS One 9:e110082

24. Papania MJ, Wallace GS, Rota PA, Icenogle JP, Fiebelkorn AP, Armstrong GL, Reef SE, Redd SB, Abernathy ES, Barskey AE, Hao L, McLean HQ, Rota JS, Bellini WJ, Seward JF (2014) Elimination of endemic measles, rubella, and congenital rubella syndrome from the Western hemisphere: the US experience. JAMA Pediatr 168:148-155

25. Raymaekers M, Smets R, Maes B, Cartuyvels R (2009) Checklist for optimization and validation of real-time PCR assays. J Clin Lab Anal 23:145-151

26. Simpson DI (1964) Zika Virus Infection in Man. Trans R Soc Trop Med Hyg 58:335-338

27. Tzeng WP, Frey TK (2003) Complementation of a deletion in the rubella virus p150 nonstructural protein by the viral capsid protein. J Virol 77:9502-9510 
28. WHOa (2005) Standardization of the nomenclature for genetic characteristics of wild-type rubella viruses. Wkly Epidemiol Rec 80:126-132

29. WHOb (2013) Rubella virus nomenclature update: 2013. Wkly Epidemiol Rec 88:337-343

30. Yermalovich MA, Semeiko GV, Samoilovich EO, Svirchevskaya EY, Muller CP, Hubschen JM (2014) Etiology of maculopapular rash in measles and rubella suspected patients from Belarus. PloS One 9:e111541

31. Zhao L, Li R, Liu A, Zhao S (2015) A novel duplex real time quantitative reverse transcription polymerase chain reaction for rubella virus with armored RNA as a noncompetitive internal positive control. J Virol Methods 219:84-89

32. Zhao LH, Ma YY, Wang H, Zhao SP, Zhao WM, Li H, Wang LY (2006) Establishment and application of a TaqMan real-time quantitative reverse transcription-polymerase chain reaction assay for rubella virus RNA. Acta Biochim Biophys Sin (Shanghai) 38:731-736

33. Zhu Z, Chen MH, Abernathy E, Zhou S, Wang C, Icenogle J, Xu W (2014) Genomic analysis of the Chinese genotype 1F rubella virus that disappeared after 2002 in China. J Med Virol $86: 2114-2121$ 